\title{
Akademik Personellerde Nepotizm ve Kronizm Düzeyleri
}

\author{
Yazar \\ Dr. Murat TURAN
}

Editör

Doç. Dr. Orcan MIZRAK 


\section{(C) Copyright 2020}

Bu kitabın, basım, yayın ve satış hakları Akademisyen Kitabevi A.Ş.'ne aittir. Anılan kuruluşun izni alınmadan kitabın tümü ya da bölümleri mekanik, elektronik, fotokopi, manyetik kağıt ve/veya başka yöntemlerle çoğaltılamaz, basılamaz, dağıtılamaz. Tablo, şekil ve grafikler izin alınmadan, ticari amaçh kullamılamaz. Bu kitap T.C. Kültür Bakanlı̆ı bandrolü ile satılmaktadır.

Not: Bu Çalışma Danışmanlığını Doç. Dr. Orcan MIZRAK'ın Yaptığı "Spor Bilimleri Fakültelerinde Görev Yapan Akademik Personelin Nepotizm Ve Kronizm Düzeylerinin İncelenmesi" Adlı Tezden Üretilmiştir.

\section{ISBN}

978-625-7275-58-3

\section{Kitap Adı}

Akademik Personellerde Nepotizm ve Kronizm Düzeyleri

\section{Yazar}

Dr. Murat TURAN

Editör

Doç. Dr. Orcan MIZRAK

\section{Yayın Koordinatörü}

Yasin Dilmen

Sayfa ve Kapak Tasarımı

Akademisyen Dizgi Ünitesi

Yayıncı Sertifika No

47518

Baskı ve Cilt

Vadi Matbaacılık

Bisac Code

SPO000000

\section{GENEL DAĞITIM}

\section{Akademisyen Kitabevi A.Ş.}

Halk Sokak 5 / A

Yenişehir / Ankara

Tel: o312 4311633

siparis@akademisyen.com

\section{www . akademisyen . com}




\section{TEŞEKKÜR}

Çalışmam süresince banda destek olan danışman hocam Sayın Doç. Dr. Orcan MIZRAK' a Sayın Doç. Dr. Emre BELLI' ye ve Dr. Öğr. Üy. M. Alparslan KURUDİREK hocalarıma bu çalışma aracılığı ile teşekkürlerimi sunarım.

Erzurum - 2020

Murat TURAN 


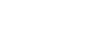

(

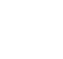

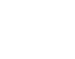

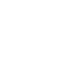

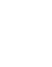

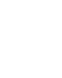




\section{IÇCiNDEKILER}

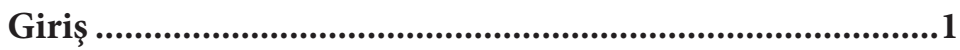

\section{KAYIRMACILIK}

1.1. Kayırmacilık Kavramı .........................................................

1.2. Kayırmacılık Türleri ...........................................................6

1.3. Kayırmacılığın Örgütler Açısından Olumsuz Ve Olumlu Etkileri ..........................................................................

1.3.1. Kayırmacılığın Olumsuz Etkileri .............................8

1.3.2. Kayırmacılı̆̆ın Olumlu Etkileri .................................9

1.4. Türkiye’de Kayırmacılık .....................................................9

1.5. Kayırmacılık İle İlgili Kavramlar ....................................12

1.5.1. Hizmet Kayırmacılı̆̆

1.5.2. Gönül Yapma ...........................................................14

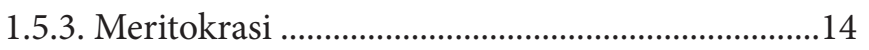

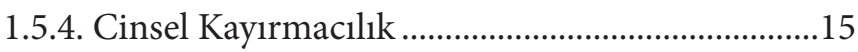

1.5.5. Pozitif Ayrımcil ${ }^{\star}$ Ik......................................................

1.5.6. Rüşvet .............................................................................16

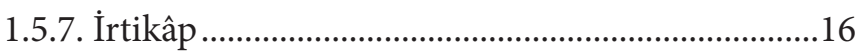

1.5.8. Rant Kollama ............................................................ 17

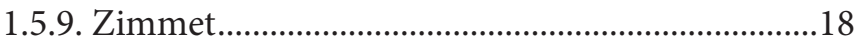

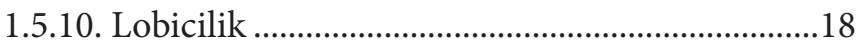

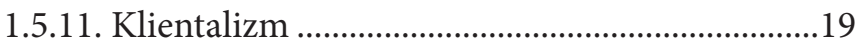

\section{NEPOTIZM}

2.1. Nepotizm Teorisinin Kaynakları ....................................21

2.2. Nepotizm Türleri ............................................................23

2.3. Ülkelerde Nepotizm .........................................................24 


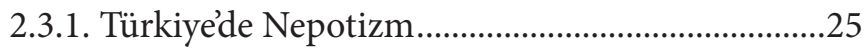

2.3.2. Diğer Ülkelerde Nepotizm ....................................25

2.4. Nepotizmin Sebepleri .......................................................28

2.5. Nepotizmin Olumlu Etkileri...........................................29

2.6. Nepotizmin Olumsuz Etkileri...........................................31

2.8. Nepotizm Hadisesinin Çözümüne Yönelik Alınabilecek

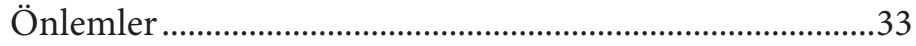

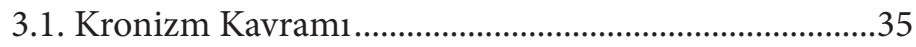

\section{KRONIZM}

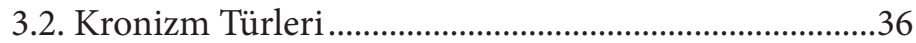

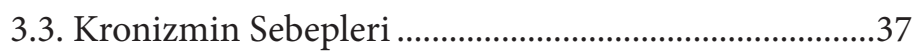

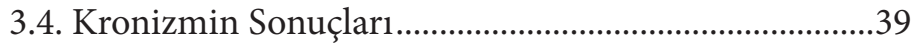

3.4.1. Kronizmin Olumlu Etkileri ....................................39

2.3.2. Kronizmin Olumsuz Etkileri...................................40

\section{MATERYAL METOT VE BULGULAR}

4.1. Materyal Ve Yöntem .........................................................41

4.1.1. Çalışma Evreni Ve Örneklem.....................................41

4.1.2. Veri Toplama Arac1................................................... 41

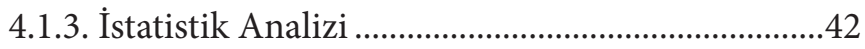

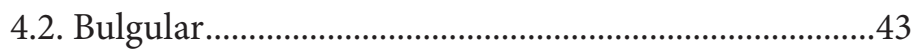

TARTIŞMA, SONUÇ VE ÖNERILLER..............................70

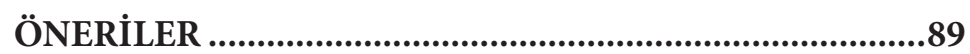

KAYNAKÇA ................................................................92

İnternet Kaynaklar1 .........................................................96 


\section{KAYNAKÇA}

Abdalla, H. F.,Mahrabi, A.S. ve Raggad, B.G. (1998). "Assessing The Perceptions of Human Resource Managers Toward Nepotism”. International Journalof Manpower. Cilt:19, Say1.8, sf:554-570.

Akalan, A.R., (2006). Türk Kamu Hizmetinde İyi Yönetim ve Yolsuzlukla Mücadele, Doktora Tezi, Selçuk Üniversitesi Sosyal Bilimler Enstitüsü, Konya.

Aközer, M. (2003). “Kamuoyu Gözüyle Kamu da Yolsuzluk”, Görüş Dergisi, Aralik-2003, ss.14-23.

Aktan, C.C., (2001), "Siyasal Ahlak ve Siyasal Yozlaşma”, Yolsuzlukla Mücadele Stratejileri”, Hak-İş Yayınları, Ankara.

Akdoğan, A. (2000) "Aile İşletmelerinin Özellikleri ve Aile İşletmelerinde Kurumsallaşma İhtiyacı”, Erciyes Üniversitesi İ.İ.B.F Dergisi, Sayı. 16.

Adil, A. (2017). Nepotizm ve İş tatmini Arasındaki İlişki ve Safranbolu Konaklama İşletmelerinde Bir Araştırma Yayımlanmış Yüksel Lisans Tezi, Karabük Üniversitesi, Sosyal Bilimler Enstitüsü, Karabük.

Ateş, Ö. (2005). “Aile Şirketlerinde Değişim ve Süreklilik”. Ankara Sanayi Odası Yayını, Yayın No:56, 12- 70, Ankara.

Asunakutlu, T. ve Avcı, U. (2010). "Aile İşletmelerinde Nepotizm Algısı ve İş Tatmini Üzerine Bir Araştırma”. Süleyman Demirel Üniversitesi İktisadi ve İdari Bilimler Fakültesi Dergisi, 15(2), 93-109.

Arasl, H. \& Tümer, M. (2008). "Nepotism, Favoritism and Cronyism: A Study of Their Effects on Job Stressand Job Satisfaction In The Banking Industry of North Cyprus", Social Behavior and Personality, 36 (9),1237-1250.

Aytaç, Ö. (2006). "Memurluk Zihniyeti ve Memuriyet Toplum: Prens Sebahattin'in Görüşleri Işı̆ğında Bir Çözümleme”. Dokuz Eylül Üniversitesi SBE, 9 (1). 1-26.

Aytaç, Ö., (2010). “Kayırmacı İlişkilerin Sosyal Temeli”, Erdem, R., (Editör). Yönetim ve Örgüt Açısından Kayırmacılık, Beta Yayınları, İstanbul.

Aydoğan, I. (2012). "Örgütlerde kayırma varlığı", Afrika Gazetesi işletme Yönetimi, 6 (12). ss 4577-4586.

Baş, F.F. (2019). Nepotizmin Çalışan Davranışları üzerindeki Etkileri, Yüksek Lisans Tezi, Bursa Uludağ Üniversitesi, Sosyal Bilimler Enstitüsü, Bursa.

Barbaros Z. (2015). Nepotizm Üzerine Bir Çalışma Kamu Özel Sektör Karşılaştırması, Yayımlanmış Yüksek Lisans Tezi, Beykent Üniversitesi, Sosyal Bilimler Enstitüsü, İstanbul

Barry B. (1975). "The Development of Organization structure in the Family Firm", Journal of General Management.

Bayhan, V., (2002). "Demokrasi ve Sivil Toplum Örgütlerinin Engelleri: Patronaj ve Nepotizm", Cumhuriyet Üniversitesi Sosyal Bilimler Dergisi, 26: 1-13, Sivas. 
Berkman, A. Ü., (2009). Gelişmekte Olan Ülkelerde Kamu Yönetiminde Yolsuzluk Ve Rüssvet, (2. Baskı), Ankara: Türkiye ve Ortadoğu Amme İdaresi Enstitüsü Yayınları, 345.

Boadi, E.G., (2000). "Conflict of Interest, Nepotism and Cronyism", Source Book 2000, 5: 195-204.

Büte, Mustafa. (2011). "Nepotizmin İş Stresi, İş Tatmini, Olumsuz Söz Söyleme ve işten Ayrılma Niyeti Üzerine Etkileri”, Ç.Ü. Sosyal Bilimler Enstitüsü Dergisi, Cilt 20, Sayı 1, ss.177-194.

Büte, M., (2011). "Kayırmacılığın Çalışanlar Üzerine Etkileri İle İnsan Kaynakları Uygulamaları İlişkisi: Türk Kamu Bankalarına Yönelik Bir Araştırma”, Atatürk Üniversitesi Sosyal Bilimler Enstitüsü Dergisi, 15: 383-404.

Büte, M. (2008). "Aile işletmelerinin Kurumsallaşma Sürecinde Yaşadığ1 Sorunlar. Bildiri”, 3. Aile işletmeleri Kongresi, Kongre Kitabı, İstanbul Kültür Üniversitesi yayını, İstanbul, 18-19 Nisan 2008, ss.1/313-332.

Craig J., ve Noel J. L. (2002) "Incorporating The Family Dynamic Into The Entrepreneur ship Process", Journal of Small Business and Enterprise Development, Volume. 9, Number.

Çınar, İ., (2009). “Kayırmacılık: Bir Kavram Çözümleme Denemesi”, Eğitişim Dergisi, 24.

Dökümbilek, F. (2010). Aile Şirketlerinde Nepotizm ve Bir Araştırma, Yayımlanmış Yüksek Lisans Tezi, Bahçe şehir Üniversitesi, Sosyal Bilimler Enstitüsü, İstanbul.

Düz, S. (2012). Konaklama İşletmelerinde Nepotizm İle Örgütsel Bă̆lllık Arasındaki İlişkinin İncelenmesi, Yayımlanmış Yüksek Lisans Tezi, Afyon Kocatepe Üniversitesi, Sosyal Bilimler Enstitüsü, Afyonkarahisar.

Drew, A., Kriz, A., Kreaing, B. ve Rowley, C. (2012). "Beyond Cronyism: In Pursuit Of Deep Trust”. Cass Knowledge, August, 1-21.

Eken, Y. (2015). Nepotizm ve Kronizmin Çalışanların Performansı Üzerine Etkisi, Yayımlanmış Yüksek Lisans Tezi, Beykent Üniversitesi, Sosyal Bilimler Enstitüsü, İstanbul.

Erdem, B., Çeribaş S. Ve Karataş, A., (2013). Otel İşletmelerinde Çalışan İş görenlerin Kronizm (Eş-Dost Kayırmacılı̆̆ı) Algıları: İstanbul'da Faaliyet Gösteren Bir, İki ve Üç Yıldızlı Otel İşletmelerinde Bir Araştırma, Çukurova Üniversitesi Dergisi, 17: 51-69, Adana.

Erdem, M. Ve Meriç, E., (2012). "Okul Yönetiminde Kayırmacılığa İlişkin Ölçek Geliştirme Çalışması”, Eğitim Bilimleri Araştırmaları Dergisi, 2: 142-154.

Fındıkçı, İ. (2005). Aile şirketlerinde yönetim ve kurumsallaşma, Alfa Yayınları, İstanbul.

George, D., \& Mallery, P. (2016). IBM SPSS statistics 23 step by step: A simple guide and reference. Routledge. 
Gümüştekin, G. E., Özler H. ve Özler D. E., (2006) "Aile İşletmelerinde Nepotizme Kurumsal Bir Bakış”. 2. Aile İşletmeleri Kongresi, Kongre Kitabı İstanbul, Kültür Üniversitesi Yayınları, 272-276.

Gürer, A. (2017). Algılanan örgütsel kronizmin çalışan sessizliği üzerindeki etkisinde Kişiliğin düzenleyici rolü: Doktora Tezi, İstanbul Arel Üniversitesi, Sosyal Bilimler Enstitüsü, İstanbul.

İlter, H. M. (2001). Aile Şirketlerinde Kurumsallaşma Ve KOBİlerin Yönetim Sorunları, İstanbul Ticaret Ve Sanayi Odası Yayın No:2001- 19, İstanbul.

İşlek, S. (2019). Aile İşletmelerinde Nepotizmin İş gören Performansı Üzerindeki Etkisi: Yüksek Lisans Tezi, Trakya Bölgesinde Bir Araştırma, Beykent Üniversitesi, Soysal Bilimler Enstitüsü, İstanbul.

İyiişleroğlu, S. (2006). Aile Şirketleri: Adana ve Çevresinde Faaliyet Gösteren Aile Şirketlerinde Nepotizm Uygulamasinın Tespitine Yönelik Bir Araştırma, Yayınlanmamış Yüksek Lisans Tezi, Çukurova Üniversitesi Sosyal Bilimler Enstitüsü.

Irak, D. (2010). "Örgütlerde Cinsiyet Ayrımcilığı ve Örgütsel Sonuçlar Üzerindeki Etkileri”. Ramazan Erdem (Ed.). Yönetim ve Örgüt Açısından Kayırmacılık içinde (s. 179-202). İstanbul: Beta Basım.

Jones, R., Stout, T., Harder, B., Levġne. E. Levġne, J. ve Sanchez, J.I.(2008) "Personel Psikolojisi ve Adam kayırma: Biz Anti-Adam kayırma Policie Destek mi? “Endüstriyel-Örgütsel Psikolog, 45 (3). pp.17-20.

Karataş, A., (2013). Otel İşletmelerinde Kronizmin İş Tatmini ve İşten Ayrılma Niyeti Üzerindeki Etkileri: Muğla İlinde Bir Araştırma, Yüksek Lisans Tezi, Balıkesir Üniversitesi Sosyal Bilimler Enstitüsü, Balıkesir.

Karahan, A. Yılmaz, H. (2014). "Nepotizm ve Örgütsel Bağlılık Arasındaki İlişkinin İncelenmesi ve Bir uygulama” Selçuk Üniversitesi İktisadi ve İdari Bilimler Fakültesi Sosyal ve Ekonomik Araștırmalar Dergisi (The Journal of Socialand Economic Research) ISSN: 2148 - 3043 / Nisan 2014 / Yil: 14 / Sayı: 27

Kaynak, İ. H. (2012). “Tarihsel Süreçte Toplumsal Değişimler, Protestanlık Tavırlar ve Dinsel Anmacılık". Tarihin Peşinde-Uluslararası Tarih ve Sosyal Araştırmalar Dergisi, 8, 193-207.

Kartal, M. (2019). İş hayatındaki kronizm Davranışlarının çalışanların örgütsel Adalet algılarına ve kurum itibarına Etkisi, Bandırma On Yedi Eylül Üniversitesi, Yüksek Lisans Tezi, Sosyal Bilimler Enstitüsü, Bandırma.

Kavak, H. (2020) Algılanan Örgütsel Kronizmin Örgütsel Muhalefet Üzerine Etkisinde Örgüte Güvenin Aracı Rolü: Adıyaman İlinde Milli Eğitim Bakanlığına Bağlı Orta Öğretim Kurumlarında Bir Araştırma, Doktora Tezi, İnönü Üniversitesi, Sosyal Bilimler Enstitüsü, Malatya.

Khatri, N. ve Tsang, E. W. K. (2003). "Antecedents and consequences of cronyismin organizations”. Journal of Business Ethics, 43(4). 289-303. 
Kılıçarslan, U. (2018). Konaklama İşletmelerinde Nepotizmin İş tatmini ve İşten Ayrılma Niyetine Etkisi: Antalya Örneği, Yayımlanmış Yüksek Lisans Tezi, Muğla Sitkı Koçman Üniversitesi, Sosyal Bilimler Enstitüsü, Muğla.

Meriç, M., (2004). "Yolsuzluk Nedenleri ve Önlemeye Yönelik Çalışmalar”, Muğla Üniversitesi Sosyal Bilimler Enstitüsü Dergisi, 12: 71-85.

Meriç, E. Ve Erdem, M. (2013). "İlköğretim Okullarında Görev Yapan Öğretmenlerin Algılarına Göre Okul Yönetiminde Kayırmacıllı”, Kuram ve Uygulamada Eğitim Yönetimi- Educational Administration: Theoryand Practice, 19: 467-498.

Nadler, J. \& Schulman, M. (2006). Favoritism, cronyism, and nepotism. http://www.scu.edu/ethics/practicing/focusareas/government_ethics/ introduction/cronyism.html. İndirme Tarihi: 20.08.2018.

Oktay, C., (1983). Yükselen İstemler Karşısında Türk Siyasal Sistemi ve Kamu Bürokrasisi, İstanbul Üniversitesi Sosyal Bilimler Enstitüsü Yayınları, İstanbul.

Ören, K. (2007). “Sosyal Sermayede Güven Unsuru ve İçgüdü Performansına Ekisi” Erciyes Üniversitesi Nevşehir İİBF İktisat Bölümü, (9)1.

Özsemerci, K. (2002). Türk Kamu Yönetiminde Yolsuzluklar, Nedenleri, Zararları ve Çözüm Önerileri, Yüksek Lisans Tezi, TODAİE, Ankara.

Özsemerci, K., (2003). Türk Kamu Yönetiminde Yolsuzluklar, Nedenleri, Zararları ve Çözüm Önerileri, Alp Yayınları, Ankara.

Özil H.T. (2019). Hemşirelerde Nepotizm Algısı ve İş Doyumu Üzerine Bir Araştırma Yayımlanmış Yüksek Lisans Tezi, Medipol Üniversitesi, Sağlık Bilimleri Enstitüsü, İstanbul

Özler, D. E. ve Büyük Arslan, A. (2011). "İçinde kayırma «Genel Görünüm Organizasyonlar: A Literature Review», Business International Journal ve Yönetim Çalışmaları, 3 (1). pp 275-285.

Özler, H.,Özler, D.N. \& Gümüştekin G.E. (2007). "Aile işletmelerinde Nepotizmin Gelişme Evreleri ve Kurumsallaşma”, Selçuk Üniversitesi Sosyal Bilimler Enstitüsü Dergisi, (17). 437-450.

Özkan, Ö. (2019). Nepotizm ve İnsan Kaynakları Arasındaki İlişkinin İncelenmesi ve Bir Uygulama, Yüksek Lisans Tezi, Beykent Üniversitesi, Sosyal Bilimler Enstitüsü, , İstanbul.

Polat, R. (2013). Orta Öğretim Kurumlarında Kronizm Algisının Örgütsel Güven Üzerine Etkisi, Yayımlanmış Yüksek Lisans Tezi, Fırat Üniversitesi, Eğitim Bilimleri Enstitüsü, Elazı̆̆.

Polat, M. (2019). Nepotizm Ve Psikolojik Sözleşme İhlallerinin Üretkenlik Karşıtı İş Davranışlarına Etkisi, Doktora Tezi, Kahramanmaraş Sütçü İmam Üniversite, Sosyal Bilimler Enstitüsü, Kahramanmaraş.

Sarıboğa, M. (2017). Nepotizmin Örgütsel Bağlllk ve İş Doyumuna Etkisi ve Otel Çalışanları Üzerine Bir Araştırma, Yüksek Lisans Tezi, Doğuş Üniversitesi, Sosyal Bilimler Enstitüsü, İstanbul. 
Savur. Z. (2018). İşgücü Devri ve Kayırmacılık (Nepotizm) Arasındaki İlişki: Otomotiv Yan Sanayisinde Bir Araştırma, Yüksek Lisans Tezi, İstanbul Üniversitesi, Sosyal Bilimler Enstitüsü, İstanbul.

Sheridan, M.K., (2007). “Just Because It's Sex Doesn't MeanIt's Because of Sex: The Need for New Legislationto Target Sexual Favoritism".

Signorotto, G. ve Visceglia, M. A. (21 March 2002). Court and Politics in Papal Rome, 1492-1700. Cambridge University Press, Cambridge.

Sorgun, C. (2007). Aile işletmelerinde Yönetim sorunları: Adana ilinde bir Araştırma, Niğde Üniversitesi Sosyal Bilimler Enstitüsü.

Tabachnick, B. G., \& Fidell, L. S. (1996). Using multivariate statistics (3rd ed.). New York: HarperCollins College Publishers.

Tarhan, R.B.,Gençkaya, Ö.F., Ergül, E., Özsemerci, K. ve Özbaran, H., (2006). "Yolsuzlukla Mücadele TBMM Raporu (Bir Olgu Olarak Yolsuzluk: Nedenler, Etkiler Ve Çözüm Önerileri)-(2. Baskı)”, Matsa Basımevi, Ankara.

Turgut, K., (2007). "Politik Yozlaşmanın İnsan Davranışları Üzerindeki Etkisi”, (http://www.stratejikboyut.com/haber/politik-yozlasmanin-insan-uzerindeki-etkisi-28067.html.). (Erişim: 09.09.2019).

Turhan, R. (2016). Nepotizm, Kronizm ve Ptronaj Eğilimlerinin Kurumsallaşma Algısı Bağlamında Analizi, Yayımlanmış Yüksek Lisans Tezi, Ege Üniversitesi, Sosyal Bilimler Enstitüsü, İzmir.

Yan, Y. ve Bei, H. (2009). "The Antecedents of Organizational Cronyism"Management and Service Science.

Yıldırım, M. (2013). "Kamu Yönetiminin Kadim Paradoksu: Nepotizm ve Meritokrasi”, Sosyal Bilimler Dergisi, 11: 354-380.

Yıldırım, M. (2013). "Kamu Yönetiminin Kadim Paradoksu: Nepotizm ve Meritokrasi”. Celal Bayar Üniversitesi Sosyal Bilimler Dergisi, 11 (2). 353-380.

Xin-Zhi, Z.,Xu, H., ve Fei, C. (2010). “The Normative Study of Cronyismon Chinese Family Business", 2010 International Conference on E-Business andE-Government, 1049-1052.

\section{INNTERNET KAYNAKLARI}

1. Rant kollama www.turkhukuksitesi.com , Erişim Tarihi: 11.01.2019

2. www.beyazgazete.com, Erişim Tarihi: 21.08.2019. 